\title{
Open Reduction and Internal Fixation with Mini-plate and Screws for Management of Unstable Metacarpal Fracture among Hand Injuries in a Tertiary Care Center: A Descriptive Cross-sectional Study
}

\author{
Sagar Panthi, ${ }^{1}$ Rishiswor Shrestha, 'Jigyasu Pradhan, ${ }^{3}$ Bikash Neupane, ${ }^{1}$ Siddhartha Khanal, ${ }^{1}$ Angelica Karki, ${ }^{2}$ \\ Deepa Sharma ${ }^{3}$ \\ 'Department of Orthopaedics and Traumatology, Rapti Academy of Health Sciences, Ghorahi, Dang, Nepal, \\ 2Department of Orthodontics and Dentofacial Orthopaedics, Rapti Academy of Health Sciences, Ghorahi, Dang, \\ Nepal, ${ }^{3}$ Department of Community Medicine and Public Health, Rapti Academy of Health Sciences, Ghorahi, \\ Dang, Nepal.
}

\section{ABSTRACT}

Introduction: Hand injuries metacarpal fractures are common and it accounts about 14 to $28 \%$. Mini-plate fixation in unstable metacarpal fractures provides absolute stability and early mobilization of fingers to reduce complications. The purpose of this study is to find out the prevalence of open reduction and internal fixation with mini-plate and screws for management of unstable metacarpal fracture among hand injuries done in a tertiary care center.

Methods: This was a descriptive cross-sectional study done from February 2019 and January 2021 in a tertiary care center with unstable isolated metacarpal fracture treated with mini-plate fixation and were followed up for six months duration. Ethical approval and informed written consent were taken from all patients. The outcome was assessed by the American Society for Surgery of the Hand Total Active Flexion Score. Convenient sampling method was used. Point estimate at 95\% Confidence Interval was calculated along with frequency and proportion for binary data. Statistical Package for Social Sciences used for analysis.

Results: Out of 250 patients who underwent hand surgeries, open reduction and internal fixation with mini-plate and screws for unstable metacarpal fracture were done in 32 (12.8\%) (8.66-16.94 at $95 \%$ Confidence Interval). The mean time of fracture union was $6.78 \pm 1.008$ weeks. Functional outcome according to American Society for Surgery of the Hand Total Active Flexion score was excellent in $25(78.2 \%)$, good in $6(18.8 \%)$, and poor in $1(3 \%)$ patient.

Conclusions: Fixation of metacarpal fracture by mini-plate and screws was required in fewer patients. Mini-plate fixation provides better stability and early mobilization for unstable metacarpal fractures to achieve a good functional outcome.

Keywords: fracture fixation; metacarpal bones; mini-plate.

\section{INTRODUCTION}

Among hand injuries metacarpal fractures are common and it accounts about 14 to $28 \%$ respectively. ${ }^{1}$ These types of injuries occur due to road traffic accidents, physical assault, and machinery injuries. ${ }^{2}$

Surgical management is one of the best options for unstable metacarpal fractures for good functional outcome..$^{3,4} \mathrm{~K}$-wire fixation either by closed or open technique is used for the management of metacarpal fractures. But these fixation devices have complications like finger stiffness, pin-tract infection and migration of K-wire. It maintains the length and alignment but rotations are not controlled by this method..$^{5,6}$

Open reduction and internal fixation with mini-plate and screws which provides rigid fixation and allows early

Correspondence: Dr. Sagar Panthi, Department of Orthopaedics and Traumatology, Rapti Academy of Health Sciences, Ghorahi, Dang, Nepal. Email: drsagarmsortho@ gmail.com, Phone: +977-9857036678. 
digital rehabilitation is preferred by various authors. ${ }^{7,8}$ This study aims to find out the prevalence of open reduction and internal fixation with mini-plate and screws for management of unstable metacarpal fracture among hand injuries done in a tertiary care center.

\section{METHODS}

A descriptive cross-sectional study was carried out at Rapti Academy of Health Sciences, Ghorahi, Dang from period February 2019 to January 2021. Ethical approval was obtained from the IRB and informed written consent was taken from all patients. All 250 patients undergoing hand surgeries were included in the study. All patients with unstable metacarpal fractures who were treated with open reduction and internal fixation with mini-plate were followed up. Intra-articular fractures open fracture, multiple metacarpal fractures, age less than 18 and above 60 years were excluded from our study. A convenient sampling method was used. The sample size was calculated using a formula according to the study done by Nakashian $\mathrm{M}$, et al. ${ }^{9}$

$$
\begin{aligned}
\mathrm{n} & =\mathrm{Z}^{2} \times \mathrm{p} \times \mathrm{q} / \mathrm{e}^{2} \\
& =1.96^{2} \times 0.13 \times 0.87 / 0.05^{2} \\
& =173
\end{aligned}
$$

Where,

$\mathrm{n}=$ minimum required sample size

$Z=1.96$ at $95 \%$ Confidence Interval $(\mathrm{Cl})$

$p=$ prevalence of open reduction and internal fixation ${ }^{9}$

$q=1-p$

$e=$ margin of error, $5 \%$

The required sample size was 173. However, total sample size taken was 250 as we used convenient sampling technique.

The surgery for all patients was done under regional anesthesia. Pre-operatively one gram of intravenous Ceftriaxone was given thirty minutes before surgery. Tourniquet was applied and a dorsal approach was used to fix the fracture by $2.0 \mathrm{~mm}$ mini-plate and screws. Post-operatively patients were kept in a below-elbow volar slab. Passive mobilization was done on the third day and active mobilization was started on the second week after slab removal. The outcome was assessed by ASSH (American Society for Surgery of Hand and Total Active Flexion) score ${ }^{10}$ at six months follow-up. Statistical analysis was done by calculating mean and standard deviation via Statistical package for Social Sciences (SPSS) software version 21.0. Point estimate at $95 \%$ Confidence Interval and descriptive frequency was calculated.

\section{RESULTS}

Out of 250 patients who underwent hand surgeries in our center, open reduction and internal fixation with miniplate and screws for unstable metacarpal fracture were done in 32 (12.8\%) (8.66-16.94\% at 95\% Confidence Interval). Among 32 patients mean age of patients was $37.78 \pm 8.31$ ranging from $20-60$ years, with a higher frequency of male $20(62.5 \%)$ than female 12 (37.5 $\%)$. The right side was more involved than the left side. Fall was the most common mechanism of injury. The transverse pattern of fracture was more common (Table 1 ). The mean time of fracture union was $6.78 \pm 1.088$ weeks.

\begin{tabular}{|lc|}
\hline \multicolumn{2}{|l|}{ Table 1. Demography of study participants $(\mathbf{n}=\mathbf{3 2})$} \\
\hline Characteristics & $\mathbf{n}(\%)$ \\
Sex & \\
Male & $20(62.5)$ \\
Female & $12(37.5)$ \\
Side & \\
Right & $21(65.6)$ \\
Left & $11(34.4)$ \\
Mechanism of Injury & \\
Fall & $15(46.9)$ \\
Physical assault & $10(31.3)$ \\
Road Traffic Accident & $7(21.8)$ \\
Fracture Pattern & \\
Transverse & $13(40.6)$ \\
Oblique & $6(18.8)$ \\
Spiral & $7(21.8)$ \\
Comminuted & $6(18.8)$ \\
Age (Years) & $37.78 \pm 8.31$ \\
Mean time of fracture union (months) & $6.78 \pm 1.088$ \\
\hline
\end{tabular}

Functional outcome at final follow-up by ASSH-TAF score was excellent in $25(78.2 \%)$ of cases, good in $6(18.8 \%)$ of cases, and poor in $1(3 \%)$ of cases (Table 2). Two patients developed superficial wound infection which resolves with oral antibiotics. In one patient we couldn't achieve a good functional outcome and developed finger stiffness. We didn't encounter complications like implant failure, malunion, non-union, and complex regional pain syndrome.

\begin{tabular}{|lc|}
\hline Table 2. Functional outcome at final follow-up by \\
American Society for Surgery of Hand and Total \\
Active Flexion (ASSH-TAF) score $(\mathbf{n}=\mathbf{3 2})$. \\
\hline Characteristics & $\mathbf{n}(\%)$ \\
Excellent & $25(78.2)$ \\
Good & $6(18.8)$ \\
Poor & $1(3)$ \\
\hline
\end{tabular}

\section{DISCUSSION}

Metacarpal fractures can be managed conservatively in many cases if the fracture pattern is stable but unstable fractures warrant surgery. ${ }^{11}$ These fractures if not treated properly, may lead to loss of function of the hand as well as reduce the quality of life. ${ }^{12,13}$

Various fixation devices are used to manage a metacarpal fracture that includes $\mathrm{K}$-wire fixation, tension band 
wiring, lag screw fixation. These fixation devices are not very stable. Fixation of unstable metacarpal fractures with mini-plate provides absolute stability which allows early mobilization of finger and prevents complications. ${ }^{1,14}$ In 1928, Lambotte described various surgical methods for the management of metacarpal fractures. It includes K-wire fixation, external fixators, a lag screw, and circlage wiring. ${ }^{9}$

Shehadi SI reported $100 \%$ functional outcome in metacarpal fractures managed by external fixators. ${ }^{15}$ Dreyfuss D, et al. did a non-randomized controlled trial study by using K-wire versus locking plate for management of metacarpal fractures in adults. Their result shows a good outcome with locking plate fixation as compared to K-wire fixation. ${ }^{16}$ Cha SM, et al. did a Quasi-experimental study comparing miniopen antegrade intramedullary nailing versus mini-plate fixation and the result was better in the mini-plate fixation group. ${ }^{17}$ Vasilakis $V$, et al. did a retrospective study comparing closed reduction and percutaneous $\mathrm{K}$-wire fixation and mini-plate fixation and their results were not significant between two different modes of treatment. ${ }^{18}$ Pandey $R$, et al. did a randomized controlled trial study comparing closed reduction and percutaneous $\mathrm{K}$-wire fixation with mini-plate fixation. On assessment at one year closed reduction percutaneous $\mathrm{K}$-wire fixation had better results than mini-plate fixation. ${ }^{19}$ Chand $\mathrm{P}$, et al. did a prospective study and concluded that $87.5 \%$ had excellent results with low profile mini-plate fixation. ${ }^{20}$

There were $62.5 \%$ male and $37.5 \%$ female. The most common mode of injury was fall which accounted for $46.9 \%$ of the total injuries. There was a significant relationship between gender and mode of injury. Physical assault was seen more in males this may be due to their more violent nature. Fifth metacarpal fractures were common. In the study done by Chand $\mathrm{P}$, et al. third and

\section{REFERENCES}

1. Gupta R, Singh R, Siwach R, Sangwan S, Magu NK, Diwan R. Evaluation of surgical stabilization of metacarpal and phalangeal fractures of hand. Indian J Orthop. 2007 Jul;41(3):224-9. [PubMed | Full Text | DOI]

2. Saaiq M. Epidemiology and management of foreign bodies in the hand: Pakistani perspective. World J Plast Surg. 2014 Jan;3(1):13-7. [PubMed | Full Text]

3. Bernstein ML, Chung KC. Hand fractures and their management: an international view. Injury. 2006 Nov;37(11):1043-8. [PubMed | Full Text | DOI]

4. Nakashian MN, Pointer L, Owens BD, Wolf JM. Incidence of metacarpal fractures in the US population. Hand (N Y). 2012 Sep;7(4):426-30. [ubMed | Full Text | DOI]

5. Klein DM, Belsole RJ. Percutaneous treatment of carpal, metacarpal, and phalangeal injuries. Clin Orthop Relat Res. 2000 Jun;(375):116-25. [ubMed | Full Text | DOI] fourth metacarpal fractures were common. ${ }^{20}$ Meantime of fracture union was $6.78 \pm 1.008$ weeks which was comparable to study done by Bașar $\mathrm{H}$, et al. ${ }^{21}$

We could achieve excellent results in $78.2 \%$, good in $18.8 \%$, and fair in $3 \%$. We achieved union in all cases. In one case we had poor results due to several factors such as a high degree of comminution of the fracture, post-operative superficial wound infection, and lack of compliance by the patient.

Two patients developed superficial wound infections which resolved with oral antibiotics. We didn't encounter complications like implant failure, malunion, non-union, and complex regional pain syndrome. Our sample size was small and $72.5 \%$ of patients belonged to the 21- 40 years age group which was comparable to the study done by Chand $P$, et al. ${ }^{20}$

\section{CONCLUSIONS}

Fixation of metacarpal fracture by mini-plate and screws was required in fewer patients. It can be a good option for treating such fractures. More studies are needed to clarify the difference in fixation with other implants in unstable metacarpal fracture. The ultimate goal is to achieve excellent to good functional outcomes and early union of the fracture.

\section{ACKNOWLEDGEMENTS}

We owe our gratitude to the Rapti Academy of Health Sciences for allowing us to use the patient data in this study. We would like to express our special thanks to the department of statistics for their support during the study. Finally, we wish to express our sincere thanks to all the patients for their co-operation who have made this study possible.

\section{Conflict of Interest: None.}

6. Lee SG, Jupiter JB. Phalangeal and metacarpal fractures of the hand. Hand Clin. 2000 Aug;16(3):323-32. [PubMed | Full Text]

7. Massengill JB, Alexander H, Langrana N, Mylod A. A phalangeal fracture model--quantitative analysis of rigidity and failure. J Hand Surg Am. 1982 May;7(3):264-70. [PubMed | Full Text | DOI]

8. Firoozbakhsh KK, Moneim MS, Howey T, Castaneda E, Pirela-Cruz MA. Comparative fatigue strengths and stabilities of metacarpal internal fixation techniques. J Hand Surg Am. 1993 Nov;18(6):1059-68. [라bMed | Full Text | DOI]

9. Nakashian M, Pointer L, Owens B, Wolf JM. Incidence of Metacarpal Fractures in the US Population. Hand (N Y). 2012;7(4):426-30. [PubMed | Full Text | DOI]

10. Soni A, Gulati A, Bassi JL, Singh D, Saini UC. Outcome of closed ipsilateral metacarpal fractures treated with mini 
fragment plates and screws: a prospective study. J Orthop Traumatol. 2012 Mar;13(1):29-33. [PubMed | Full Text | $\underline{\mathrm{DOI}}$

11. Green DP, Hotchkiss RN, Pederson WC, Wolfe SW, editors. Green's operative hand surgery. 5th ed. Philadelphia: Elsevier Churchill Livingstone;2005. p. 286-94. Available from: https://www.google.co.in/books/edition/Green_s_ Operative_Hand_Surgery/IC_lAQAACAAJ?hl=en. [ [Full Text]

12. Freeland AE, Geissler WB, Weiss AP. Operative treatment of common displaced and unstable fractures of the hand. J Bone Joint Surg Am. 2001 Jun;83(6):928-45. [Full Text]

13. Bannasch $\mathrm{H}$, Heermann AK, Iblher $\mathrm{N}$, Momeni $\mathrm{A}$, Schulte-Monting J, Stark GB. Ten years stableinternal fixation of metacarpal and phalangeal hand fractures-risk factor and outcome analysis show no increase of complications in the treatment of open compared with closed fractures. J Trauma. 2010 Mar;68(3):624-8. [PubMed | Full Text | DOI]

14. Trevisan C, Morganti A, Casiraghi A, Marinoni EC. Low severity metacarpal and phalangeal fractures treated with miniature plates and screws. Arch Orthop Trauma Surg. 2004 Oct;124(10):675-80. [PubMed | Full Text | DOI]

15. Shehadi SI. External fixation of metacarpal and phalangeal fractures. J Hand Surg Am. 1991 May;16(3):544-50. [ubMed | Full Text | DOI]

16. Dreyfuss D, Allon R, Izacson N, Hutt D. A comparison of locking plates and intramedullary pinning for fixation of metacarpal shaft fractures. Hand (N Y). 2019 Sep;14(1):27-33. [ $\underline{\text { PubMed }}|\underline{\text { Full Text }}| \underline{\text { DOI] }}$

17. Cha SM, Shin HD, Kim YK. Comparison of low-profile locking plate fixation versus antegrade intramedullary nailing for unstable metacarpal shaft fractures--a prospective comparative study. Injury. 2019 Dec;50(12):2252-8. [PubMed | Full Text | DOI]

18. Vasilakis V, Sinnott CJ, Hamade M, Hamade H, Pinsky BA. Extraarticular metacarpal fractures: closed reduction and percutaneous pinning versus open reduction and internal fixation. Plast Reconstr Surg Glob Open. 2019 May;7(5):e2261. [PubMed | Full Text | DOI]

19. Pandey R, Soni N, Bhayana H, Malhotra R, Pankaj A, Arora SS. Hand function outcome in closed small bone fractures treated by open reduction and internal fixation by mini plate or closed crossed pinning: a randomized controlled trail. Musculoskelet Surg. 2019 May;103(1):99-105. [PubMed | Full Text $\mid \underline{\text { DOI] }}$

20. Chand P, Thapa BB, Joshi A. Early experience with low profile plate osteosynthesis for metacarpal fracture. J Nepal Health Res Council. 2009;7(1):19-24. [Full Text | DOI]

21. Basar H, Basar B, Kirbiz A. Functional results of osteosynthesis with mini-plate and screws in metacarpal fractures. Journal of Acute Disease. 2014 Dec;3(3):221-3. [Full

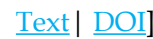

This work is licensed under a Creative Commons Attribution 4.0 International License. The images or other third party material in this article are included in the article's Creative Commons license, unless indicated otherwise in the credit line; if the material is not included under the Creative Commons license, users will need to obtain permission from the license holder to reproduce the material. To view a copy of this license, visit http://creativecommons.org/licenses/by/4.0/ 